\title{
Effects of learning on retailer ordering policy for imperfect quality items with trade credit financing
}

\author{
Mahesh Kumar Jayaswal $^{a}$, Isha Sangal ${ }^{a}$, Mandeep Mittal ${ }^{b^{*}}$ and Sarthak Malik ${ }^{c}$
}

\author{
${ }^{a}$ Department of Mathematics and Statistics, Banasthali Vidyapith, Banasthali, Rajasthan-304022, India \\ ${ }^{b}$ Department of Mathematics, Amity School of Engineering and Technology, New Delhi 110061, India \\ ${ }^{c}$ Department of Computer Science, Amity School of Engineering and Technology, New Delhi 110061, India \\ C H R O N I C L E

\section{A B S T R A C T}

Article history:

Received February 2, 2018

Accepted May 232018

Available online

May 232018

Keywords:

$E P Q$

Learning effects

Imperfect items

Trade-credit financing
Learning curves monitor the performance of workers for the given new task as well as it is a mathematical representation of the same learning process which can be analyzed after frequent repetitions. Now-a-days learning curve is a promotion effective tool for management concern with designing and controlling the process of imperfect production and redesigning unbalanced business operations in the production of goods or services related to scheduling, uncontrolled inventory management, quality management as well as inspection. Learning effect has direct impact in calculation of profit or loss. Generally, a business seller, in order to increase his sale prefers to lend his products to buyers for a definite period of time. There is no penalty before or during this definite time period however after the duration of lending time period is over, he will assign some extra charges. For this action, seller offers a trade credit financing period to his buyer. Assuming when buyer receives a lot he separates the defective and non-defective items by a screening process and defective items are then sold at a discounted price. The percentage of defective items decreases per lot according to learning curve. Seller too plans which condition is beneficial for good co-ordination of retailers and analysts. Different cases are explained broadly in this model to get maximum profit. In this paper, a fiscal construction feature model for imperfect quality items with trade credit policy is analyzed under the effects of learning. Total profit function per cycle has been derived with the help of involvement of different costs and related parameters for the retailers and a numerical example given ahead shows the verification of results. The impacts of key parameters of the model are studied by sensitivity analysts to deduce managerial insights.

(C) 2019 by the author; 1 icensee Growing Science, Canada

\section{Introduction}

Since the formulation of economic order quantity where Harris (1913) first derived square root formula for the economic order quantity, several investigations have been undertaken to expand the fundamental economic production model by different kinds of assumptions. Jaggi and Aggarwal (1996) supposed various types of ordering systems for the decaying items under trade-credit financing. Further, Salameh and Jaber (2000) improved the conventional economic production quantity/economic order quantity model for the defective quality things. Chang (2004) discussed an application in real life of fuzzy set

* Corresponding author

E-mail address: mittal mandeep@yahoo.com (M. Mittal) 
concept for the mathematical model formulation to improve the economic model for defective characteristic items and explained about the perfect and imperfect items on the basis of feature. Learning curve (LC) was first developed by Wright, which is a mathematical tool. In 1936 in his first attempt, he derived the mathematical formula which shows relationships between learning variables and quantitative shape and got result in the proposition of the LC. There is a scarcity of the review on forgetting curves. This scarcity of study has been credited almost certainty to the sensible difficulties occupied in getting information regarding the period of forgetting which is function of time, (Globerson et al., 1989).

Hammer (1957) discussed on the logical revise of LC as a way of involving work values. Baloff (1966) discussed about the mathematical behavior of the learning theory (learning slope varied widely and also explained the justification outcomes of a practical outcomes to prepare the learning curve parameters and developed skill and tentative studies in collection learning). Cunningham (1980) discussed learning rates (LR) by using different types of data, i.e. composed learning rates reported in 15 diverse U.S. industries between the years (1860-1978) and Dutton (1984) justified learning rates under distribution in 108 forms. Argote et al. (1990) discussed about the factors in which the rate of learning vary in different situations. Salameh et al. (1993) considered a limited manufacture stock form (Production inventory model) with the outcome of human knowledge and also discussed variable demand rate and learning in time to optimize the cost. Jaber et al. (1996a) explained the theory of forgetting using manufacture breaks, learning curve and discussed optimal manufacture amount and minimized the whole stock price. Jaber et al. (1996b) worked on assuming the optimal lot sizing using the condition of bounded learning cases and focused on economic order quantity (EOQ) and minimization of the whole stock cost by the help of learning curves.

Jaber et al. (1997) discussed on a comparative study of learning and forgetting theory, focused on the comparison of different types of models such as VRVF, VRIF and LFCM. Jaber et al. (1995) discussed about optimal lot sizing with shortage and backordering under learning consideration. Jaber et al. (2008) discussed the EOQ model for imperfect quality items with defective percentage per batch decreased according to the LC. Jaber and Bonney (2003) considered the lot shape with theory of learning as well as forgetting in set-up and in manufactured goods excellence and focused on minimizing production time, reducing rework process and optimizing production quantity. Balkhi (2003) discussed on maximum manufacture lot volume for decaying items and shortage case material with time unreliable order and rates with the help of impact of learning. Jaber et al. (2004) presented a model on learning curve for process generating defects required reworks and generated rate defects as stable and modified by Wright on learning curve.

Khan et al. (2010) considered an EOQ formulation for things with defective feature using learning in screening and maximized production and minimizing the cost of production. Jaber et al. (2010) discussed on how to develop a merger of average dispensation time process to give way with respect to the number of lots and planned the consequence as unreliable in the learning curve parameters manufactured and revised for developed models. Anzanello and Fogliatto (2011) suggested on different kinds of the applications of learning curves models and the authors focused on how to use this model in different mathematical forms. Konstantaras et al. (2011) developed a model to maximize production under the condition of shortages for the imperfect items with inspection as learning. Jaggi et al. (2013) discussed on production inventory model by financing policies of imperfect items under acceptable backlogging case. Jaber et al. (2013) considered a manufacture stock model with LC and FC "learning and forgetting" theory in manufacture and also discussed the minimization of the number of order (shipments) of a batch from manufacture to the subsequent cycle. Sair et al. (2014) discussed on lot size policies in EPQ models under the learning curve production costs with trade credit. 
In this paper, we consider that seller has imperfect quality items in which percentage of defective items follows learning curve that has seen already in the mathematical formulation developed by Jaber (2008). Assuming that, seller allows a definite credit time for settling the amount for his buyer to increase the sales and profit. If the buyer pays on or before the definite time, then he will not have to pay surcharge and if he returns the amount after this definite time he will have to pay surcharge. The buyer accepts such type of offer to increase profit and buyer starts a day-to-day dealing of items from the seller. Buyer separates defective and non-defective items by a screening process, after that defective item are sold at discounted price. After modeling, the situation is optimized for order quantity and profit function with the help of necessary conditions of optimization for the buyer. The order quantity decreases due to separation of defective items and profit increases due to depreciation of cost per shipment. Finally this paper explains that trade credit financing is a good promotional tool for buyer, provided by seller with imperfect quality items under learning effects. An extensive sensitivity analysis has also been performed to study the effect of $M, I_{e}, I_{p}$ and $p(n)$ on order quantity and total profit.

In the present paper, a generalized EPQ mathematical representation (model) is improved. Order rate is unfocused in scenery to scope up with the improbability in market demand. Impacts of the LC (learning curve) on the profit function are used under the trade credit. All the $\mathrm{L} \mathrm{C}$ representations are settled to the composed fact and the 'S-formed logistic LC' is set up to robust, and it is of shape $\left(p(n)=a /\left(g+e^{b . n}\right)\right)$, where $b, g>0$ and $a>0$ are the proposed model parameters and $p(n)$ is defective percentage item in the batch with number of order $n$.

\section{Table 1}

Contribution of different authors

\begin{tabular}{lccc}
\hline Author(s) & Learning Effects & Inspection & Trade credit financing \\
\hline Write (1936) & $\checkmark$ & & \\
Hammer (1957) & $\checkmark$ & & \\
Baloff (1966) & $\checkmark$ & & \\
Cunnigham (1980) & $\checkmark$ & & \\
Dutton (1984) & $\checkmark$ & $\checkmark$ & \\
Argote et al. (1990) & $\checkmark$ & $\checkmark$ & \\
Salameh et al. (1993) & $\checkmark$ & $\checkmark$ & \\
Jaber et al. (1996a) & $\checkmark$ & $\checkmark$ & \\
Jaggi et al. (1996b) & & $\checkmark$ & \\
Jaber et al. (2000) & $\checkmark$ & $\checkmark$ & \\
Jaber et al. (2008) & $\checkmark$ & & \\
Khan et al. (2010) & $\checkmark$ & & \\
Anazanello et al. (2011) & $\checkmark$ & & \\
Jaggi et al. (2013) & $\checkmark$ & $\checkmark$ \\
Teng et al. (2014) & $\checkmark$ & $\checkmark$ \\
Khan et al.(2014) & & & \\
Givi et al. (2015) & & \\
Sarkar (2016) & $\checkmark$ & & \\
Sangal et al.(2016) & $\checkmark$ & $\checkmark$ & \\
Sangal et al.(2017) & $\checkmark$ & & \\
This paper & & \\
\hline
\end{tabular}

The present paper is prearranged as follows - notations and assumptions are specified in part 2, the mathematical formulations (presentation of model) are specified in part 3. Some related numerical examples are illustrated to show the verification of the result to demonstrate the present model in part 4. Sensitivity /observation analysis is depicted in part 5 based on the input parameters used to determine the effectiveness of this model. The significance of this paper and the concluding remarks are discussed in part 6 and part 7 respectively. Finally, the references are cited in part 8. 


\section{Notations and Assumptions}

\subsection{Notations}

The subsequent notations have been incorporated to improve the present model.

Decision variable

$y_{n}$ Lot size for the $\mathrm{n}^{\text {th }}$ batch where, $n \geq 1$ (in units) per year.

Parameters

$D \quad$ Demand rate measured in units per unit of time (units / years)

$c \quad$ Unit purchasing price (\$/units)

$K \quad$ Set up price per shipment (\$/cycle)

$h \quad$ Carrying cost per unit per unit of time (\$/units)/ year

$p(n) \quad$ Defective percentage per batch (n) in $y n$ (units)

$s \quad$ Unit selling cost (price) per perfect feature unit (\$ / units)

$v \quad$ Unit discounted price per imperfect feature unit, $c>v(\$ /$ units $)$

$T_{n} \quad$ Cycle length for shipment/order (year)

$\chi \quad$ Screening rate calculated in units per unit of time, where, $D<\chi(\$ /$ units / year $)$

$d \quad$ Unit screening cost (\$/ units)

$t_{n} \quad$ Time to screen $y_{n}$, where $t_{n}=y_{n} / \chi<T_{n}$ (year)

$p \quad$ Unit selling price of perfect quality items ( $\$$ / units)

$c_{s} \quad$ Unit selling cost of defective feature quality items, $c_{s}<p(\$ /$ units $)$

$I_{e} \quad$ Interest gained per unit $(\$ /$ year $)$

$I_{p} \quad$ Interest charged per unit $(\$ /$ year $)$

$T R \quad$ Total revenue in $\$$

TC Total cost in $\$$

$\psi_{j}(Q)$ Retailer's total profit per cycle $($ in $\$)$

\subsection{Assumptions}

The subsequent assumptions have been incorporated to expand the present model

1. The demand rate for an item is known.

2. The demand is fulfilled and no shortage is allowed.

3. The rate of replenishment is immediate.

4. Lead time is zero and insignificant.

5. The seller provides a predetermined credit period to clear up the accounts to the seller.

6. Screening and demand occurs simultaneously and $\chi>D$.

7. It is assumed that each lot size receives some defective items.

8. It is assumed that the defective percentage items follow the Wright's curve and the price of the good items is considered to be greater than that of the imperfect quality items.

9. It is assumed that the rate of interest gained (earned) is less than the rate of interest paid (charged). 


\section{Model formulation}

This paper improves a mathematical formulated model for imperfect items under trade- credit financing as it has been assumed that $\chi>D$. The working process of this mathematical model is depicted in Fig. 1. It has been assumed that a batch of $y_{n}$ units go into the inventory structure at time, $t=0$ and the batch contains $p(n)$ defective items percentage with the $\mathrm{n}^{\text {th }}$ shipment items in this batch. The process of screening is finished for the total received batch at a rate of $\chi$ units per unit time to separate the good and the poor quality items. After the closing stages of screening at time $t_{n}$, the imperfect items which are equal to $p(n) y_{n}$ are sold instantaneously as a single lot at discounted cost of $c_{s}$. After this, the inventory stage slowly reduces due to the order of inventory and inventory at $T_{n}$ is zero. Consequently, different individual parts are calculated as follows,

(a) Sales return, which is equal to the total sum of income made by the order meet up during the range of period $\left(0, T_{n}\right)$ by the trade of defective feature things is

$T R=s(1-p(n)) y_{n}+v p(n) y_{n}$.

(b) Set up (ordering Cost) $=K$

(c) Purchasing price $($ cost $)=c y_{n}$

(d) Inspection (Screening) Cost $=d y_{n}$

(e) Holding Cost $=h\left(T_{n}\left(1+(-p(n)) y_{n}\right) / 2+y n^{2} p(n) / \chi\right)$

Now whole cost per cycle is given by

$$
T C=K+c y_{n}+d y_{n}+h\left(T_{n}\left(1+(-p(n)) y_{n}\right) / 2+y n^{2} p(n) / \chi\right)
$$

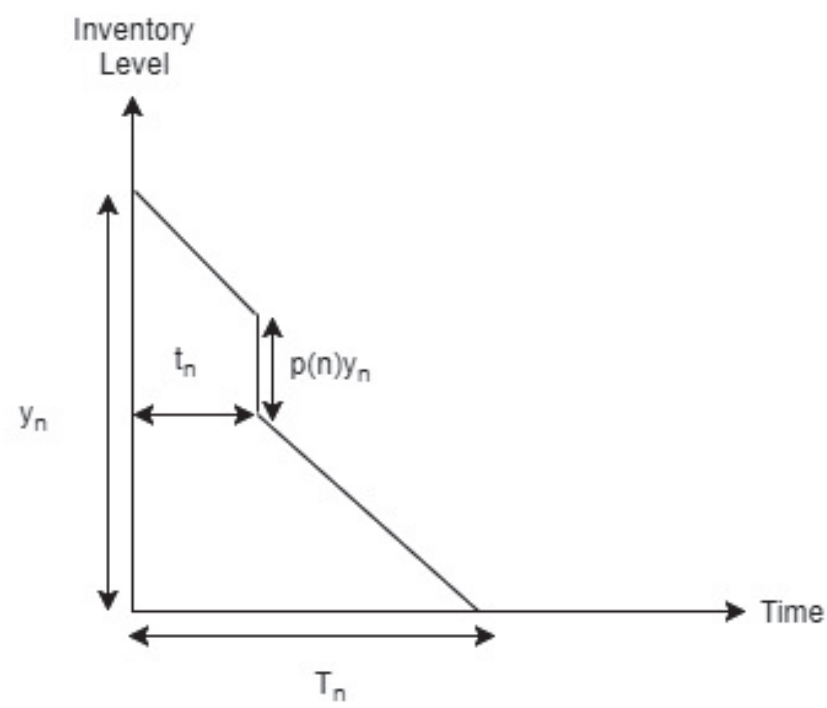

Fig. 1. Inventory structure with assessment

The cycle length $T_{n}$ for the planned inventory form is specified by

$$
T_{n}=\frac{(1-p(n)) y_{n}}{D}
$$


and time to screen $y_{n}$ units ordered per cycle

$$
t_{n}=\frac{y_{n}}{\chi} \text {. }
$$

The supplier offers the customer a predetermined credit period, say $M$ to inspire sales. As result, depending on the credit period, there are three separate conditions for the purchaser.

(i) $\quad T_{n} \geq t_{n} \geq M$

(ii) $\quad T_{n} \geq M \geq t_{n}$

(iii) $\quad M \geq T_{n} \geq t_{n}$

Since, the supplier's whole profit $\psi_{j}\left(y_{n}\right), j=1,2$ and 3 contains the subsequent components: $\psi_{j}\left(y_{n}\right)=$ Sales income (revenue) - set up cost - Purchasing price-Inspection cost -Carrying cost + Interest gained - Interest charged .

The retailer's profit per unit of time

$$
\psi_{j}\left(y_{n}\right)=\frac{T R-T C+\text { Interest earned }- \text { Interest ch } \arg e d}{T_{n}}, j=1,2,3 \text { viz }
$$

The interest charged and gained for three different cases are calculated as under

Case1: $T_{n} \geq t_{n} \geq M$

The buyer's gain interest at rate $I_{e}$ on the average sales income is generated for the period 0 to $M$. Further, the buyer has to settle the account at credit period $M$ and must arrange for the finances to pay the seller for the lasting inventory store at the pre decided rate of interest, $I_{p}$, from $M$ to $T_{n}$ and for the imperfect quality items from $M$ to $t_{n}$. Therefore, the buyer's earned interest for the average inventory during the time period 0 to $M$ is. $I_{e} p D M^{2} / 2$ and the buyer's paid interest for the unsold items after $M$ is equal to $c . I_{p} T_{n} D\left(T_{n}-M\right)^{2} / 2+c I_{p} p(n) y_{n}\left(t_{n}-M\right)$. Hence, the total revenue and total cost of the buyer for this case is depicted by

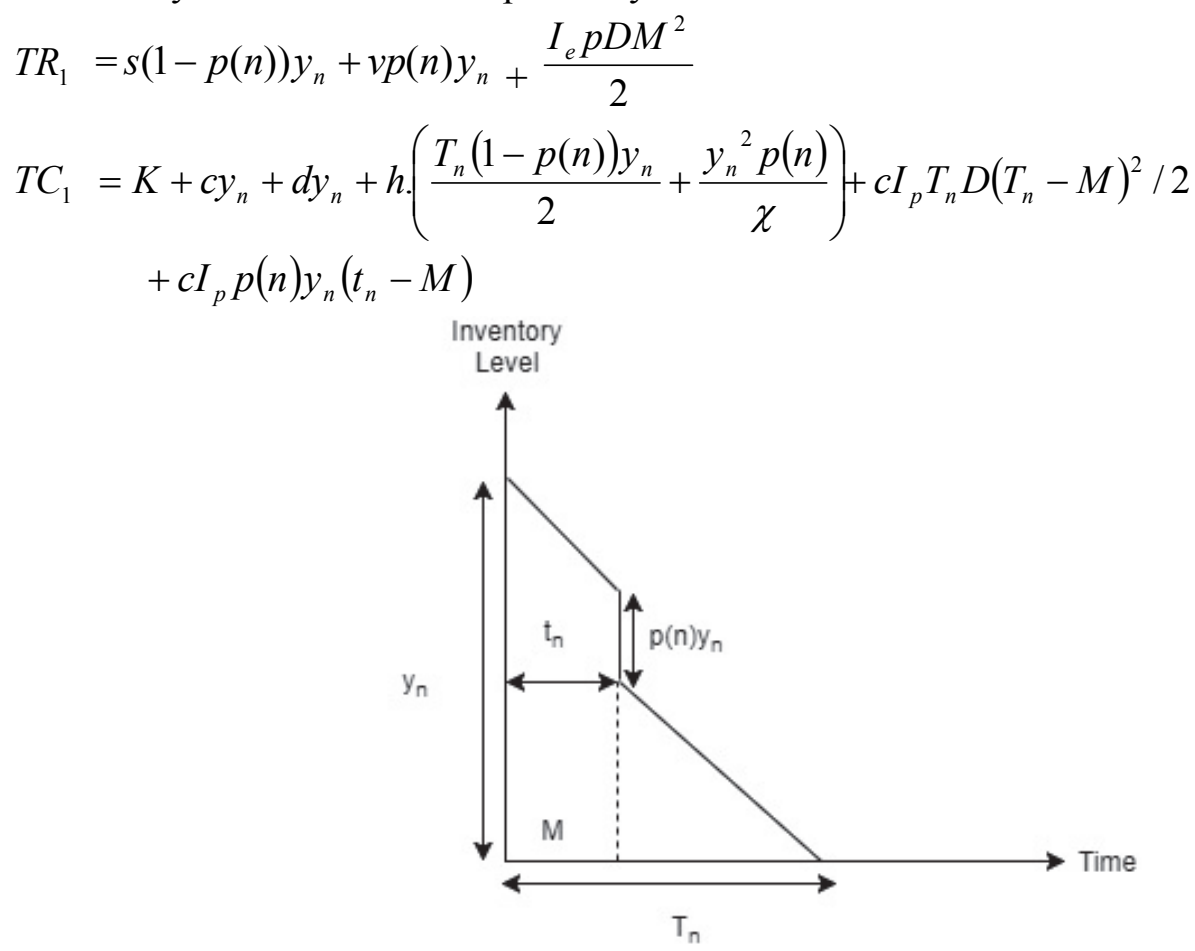

Fig. 2. Structure of inventory under inspection for the case-1 $T_{n} \geq t_{n} \geq M$ 
Total profit per cycle,

$$
\begin{gathered}
\psi_{1}\left(y_{n}\right)=\frac{T R_{1}-T C_{1}}{T_{n}} \\
=s D+\frac{v D p(n)}{1-p(n)}+\frac{D^{2} \cdot M^{2}\left(I_{e} p-I_{p} c\right)}{2(1-p(n)) y_{n}}-\frac{K D}{(1-p(n)) y_{n}} \\
-\frac{\left(c+d-c_{s} I_{p} p(n) \cdot M-c \cdot I_{p}(1-p(n) M) D\right.}{1-p(n)}- \\
\frac{\left[h\left(\frac{(1-p(n))^{2}}{2 D}+\frac{p(n)}{\chi}\right)+\frac{c \cdot I_{p}(1-p(n))^{2}}{2 D}+\frac{c_{s} I_{p} p(n)}{\chi}\right] y_{n} D}{1-p(n)}
\end{gathered}
$$

Case -2: $T_{n} \geq M \geq t_{n}$

The retailers not only gain interest rate $I_{e}$ on the income generated for the common sales from 0 to $M$, but also gain interest on the revenue generated by the sales of the imperfect quality items at discounted price from $t_{n}$ to $M$. Further, the buyer has to balance the account at the credit time period $M$ and must give the seller for the lasting store at a specified rate of charge, $I_{p}$ for the time period $M$ to $T_{n}$. The buyer's gained interest for the case is $p I_{e} D(M)^{2} / 2+c_{s} I_{e} p(n) y_{n}\left(M-t_{n}\right)$ and the buyer's paid interest for unsold items after $M$, is equal to $c I_{p} D T_{n}\left(T_{n}-M\right)^{2} / 2$.

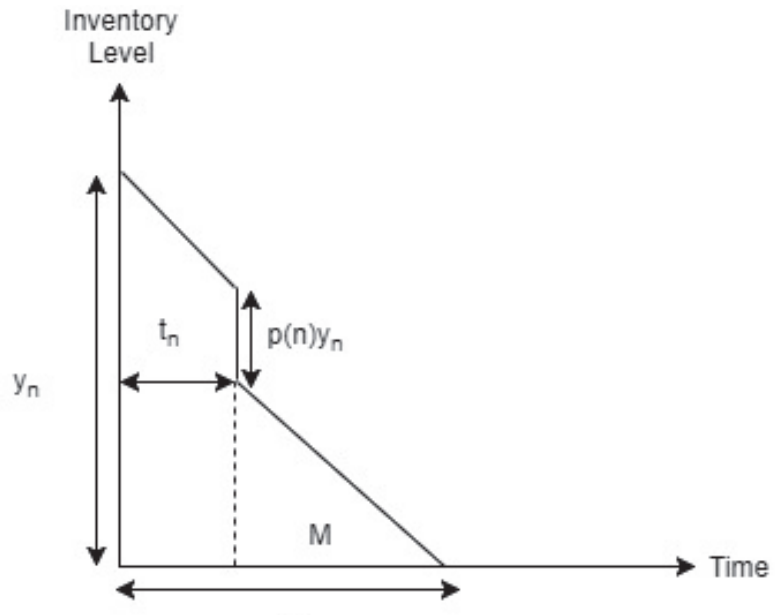

$\mathrm{T}_{\mathrm{n}}$

Fig. 3. Inventory structure and inspection with case- $2 T_{n} \geq M \geq t_{n}$

Hence, the total revenue and total cost of the buyer for the case is depicted as follows,

$$
\begin{array}{r}
T R_{2}=s y_{n}(1-p(n))+v y_{n} p(n)+\frac{p I_{e} D M^{2}}{2}+c_{s} I_{e} p(n) y_{n}\left(M-t_{n}\right) \\
T C_{2}=K+(c+d) y_{n}+h\left[\frac{y^{2}{ }_{n}(1-P(n))^{2}}{2 D}+\frac{p(n) y_{n}{ }^{2}}{\chi}\right]+\frac{c I_{p} D\left(T_{n}-M\right)^{2}}{2}
\end{array}
$$

Total profit per cycle

$$
\left(\psi_{2}\left(y_{n}\right)\right)=\frac{T R_{2}-T C_{2}}{T_{n}}
$$




$$
\begin{aligned}
& =s D+\frac{\left[v p(n)+c_{s} I_{e} p(n)\left(M-t_{n}\right)-(c+d)+c I_{p}(1-p(n)) M\right]}{1-p(n)} D+\frac{D^{2} \cdot M^{2}\left(p I_{e}-c I_{P}\right)}{2(1-p(n)) y_{n}} \\
& -\frac{y_{n}\left[h(1-p(n))^{2} \chi+2 \cdot D \cdot P(n)+\chi c I_{p}(1-p(n))^{2}-2 \cdot D c_{s} \cdot I_{e} p(n)\right]}{2 \chi(1-p(n))}-\frac{K D}{(1-p(n)) y_{n}}
\end{aligned}
$$

Case-3: $M \geq T_{n} \geq t_{n}$

In this case, no interest is payable by the buyer, who only earns interest on the revenue generated from the sales of non-defective and defective items (see Fig. 4). Therefore, the buyer's earned interest is $p I_{e} D\left(T_{n}\right)^{2} / 2+c_{s} I_{e} p(n) y_{n}\left(M-t_{n}\right)+p I_{e} D T_{n}\left(M-T_{n}\right)$,

and the paid interest is zero.

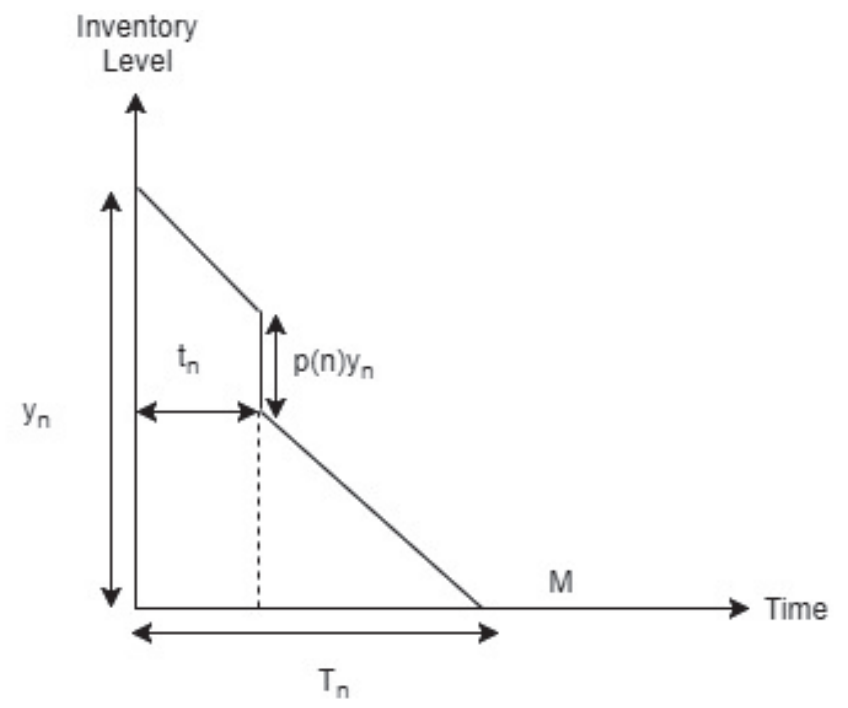

Fig. 4. Structure of inventory with inspection for the case $-3 M \geq T_{n} \geq t_{n}$

Thus, the total sales revenue and total cost of the buyer for the case 3 are given by

$$
T R_{3}=s(1-p(n)) y_{n}+v p(n) y_{n}+\frac{I_{e} p D T_{n}^{2}}{2}+c_{s} I_{e} p(n) y_{n}\left(M-t_{n}\right)+p I_{e} D T_{n}\left(T_{n}-M\right)
$$

and

$$
T R_{3}=s(1-p(n)) y_{n}+v p(n) y_{n}+\frac{I_{e} p D T_{n}^{2}}{2}+c_{s} I_{e} p(n) y_{n}\left(M-t_{n}\right)+p I_{e} D T_{n}\left(T_{n}-M\right)
$$

Total profit per cycle,

$$
\begin{aligned}
& \psi_{3}\left(y_{n}\right)=\frac{T R_{3}-T C_{3}}{T_{n}} \\
& \psi_{3}\left(y_{n}\right)=s \cdot D+v \cdot D \frac{p(n)}{1-p(n)}+\frac{I_{e} p(-p(n)+1) y_{n}}{2}+\frac{c_{s} \cdot I_{e} p(n)\left(M-t_{n}\right) D}{1-p(n)}-\frac{K D}{(-p(n)+1) y_{n}} \\
& -\frac{(c+d) D}{1-p(n)}-\frac{h y_{n}\left[\left(1-p(n)^{2} \chi+2 p(n) D\right]\right.}{2(1-p(n)) \chi}+p \cdot I_{e} D \cdot M-p \cdot I_{e}(-p(n)+1) y_{n}
\end{aligned}
$$

Therefore, the whole profit per unit time for sellers is given by 


$$
\Psi\left(y_{n}\right)=\left\{\begin{array}{lll}
\Psi_{1}\left(y_{n}\right), & T_{n} \geq t_{n} \geq M & \text { Case }-1 \text { Equation }(9 a) \\
\Psi_{2}\left(y_{n}\right), & T_{n} \geq M \geq t_{n} & \text { Case }-2 \text { Equation }(9 b) \\
\Psi_{3}\left(y_{n}\right), & M \geq T \geq t_{n} & \text { Case }-3 \text { Equation }(9 c)
\end{array}\right.
$$

\section{Solution procedure}

Let us consider that the optimal value of $y_{n}=y_{n}^{*}$ which maximizes the total gain per unit time, $\psi\left(y_{n}\right)$ may be calculated by solving the Eq. (9) for the case (1-3). The objective is to obtain the finest (optimal) worth of $y_{n}$, which maximizes the entire gain of the buyer. Therefore, the necessary and sufficient conditions for the total profit per unit time must be satisfied, similar to case 1. The optimal order quantity can be obtained by differentiating Eq. (6) with respect to $y_{n}$ and equating it to zero. Similarly proceed in case 2 and case 3 .

\subsection{Solution procedure for case -1}

For maximum profit,

$$
\frac{d \psi_{1}\left(y_{n}\right)}{d y_{n}}=0
$$

This gives the optimal, $y_{n}=\stackrel{*}{*}_{n}$, for case- 1

$$
y_{n}^{*}=\sqrt{\frac{\left[2 K-D M^{2}\left(I_{e} p-c I_{p}\right)\right] D \chi}{h\left((-p(n)+1)^{2} \chi+2 \cdot D p(n)\right)+\chi c I_{p}(-p(n)+1)^{2}+2 D c_{s} I_{p} p(n)}}
$$

Then maximum gain per cycle for the case- 1 is

$$
\psi_{1}\left(\begin{array}{c}
* \\
y_{n}
\end{array}\right)=\frac{T R_{1}-T C_{1}}{T_{n}}
$$

Thus, for the whole gain per cycle to be concave, the subsequent sufficient condition(s)should be fulfilled.

$$
d^{2} \psi_{1}\left(y_{n}\right) / d y_{n}^{2}<0, \quad \forall y_{n}>0
$$

\subsection{Solution procedure for case2}

For maximum profit,

$$
\begin{aligned}
& \frac{d \psi_{2}\left(y_{n}\right)}{d y_{n}}=0 \\
& y_{n}^{*}=\sqrt{\frac{2 K D \chi-D^{2} M^{2} \chi\left(p I_{e}-c I_{P}\right)}{h\left(\left(1-p(n)^{2} \chi+2 D p(n)\right)+\chi c I_{p}(1-p(n))^{2}-2 D c_{s} I_{e} p(n)\right.}}
\end{aligned}
$$

Then maximum worth per cycle for the case -2

$$
\psi_{2}\left(\begin{array}{c}
* \\
y_{n}
\end{array}\right)=\frac{T R_{2}-T C_{2}}{T_{n}}
$$

For the whole worth to be concave, the subsequent sufficient condition should be fulfilled. 


$$
d^{2} \psi_{2}\left(y_{n}\right) / d y_{n}^{2}<0, \quad \forall y_{n}>0
$$

\subsection{Solution procedure for case-3}

For maximum profit,

$$
\begin{aligned}
& \frac{d \psi_{3}\left(y_{n}\right)}{d y_{n}}=0 \\
& y^{*}{ }_{n}=\sqrt{\frac{2 K D \chi}{2 c_{s} I_{e} p(n) D+h\left(\left(1-p(n)^{2} \chi+2 D p(n)\right)+p I_{e} \chi(1-p(n))^{2}\right.}}
\end{aligned}
$$

Then maximum gain (profit) per cycle for the case -3

$$
\psi_{3}\left(\begin{array}{c}
* \\
y_{n}
\end{array}\right)=\frac{T R_{3}-T C_{3}}{T_{n}}
$$

For the profit per unit time to be concave, the subsequent sufficient condition should be fulfilled.

$$
d^{2} \psi_{3}\left(y_{n}\right) / d y_{n}{ }^{2}<0, \quad \forall y_{n}>0
$$

The concavity for the whole worth function is also recognized graphically for case- 2 and is shown below (see Fig. 5)

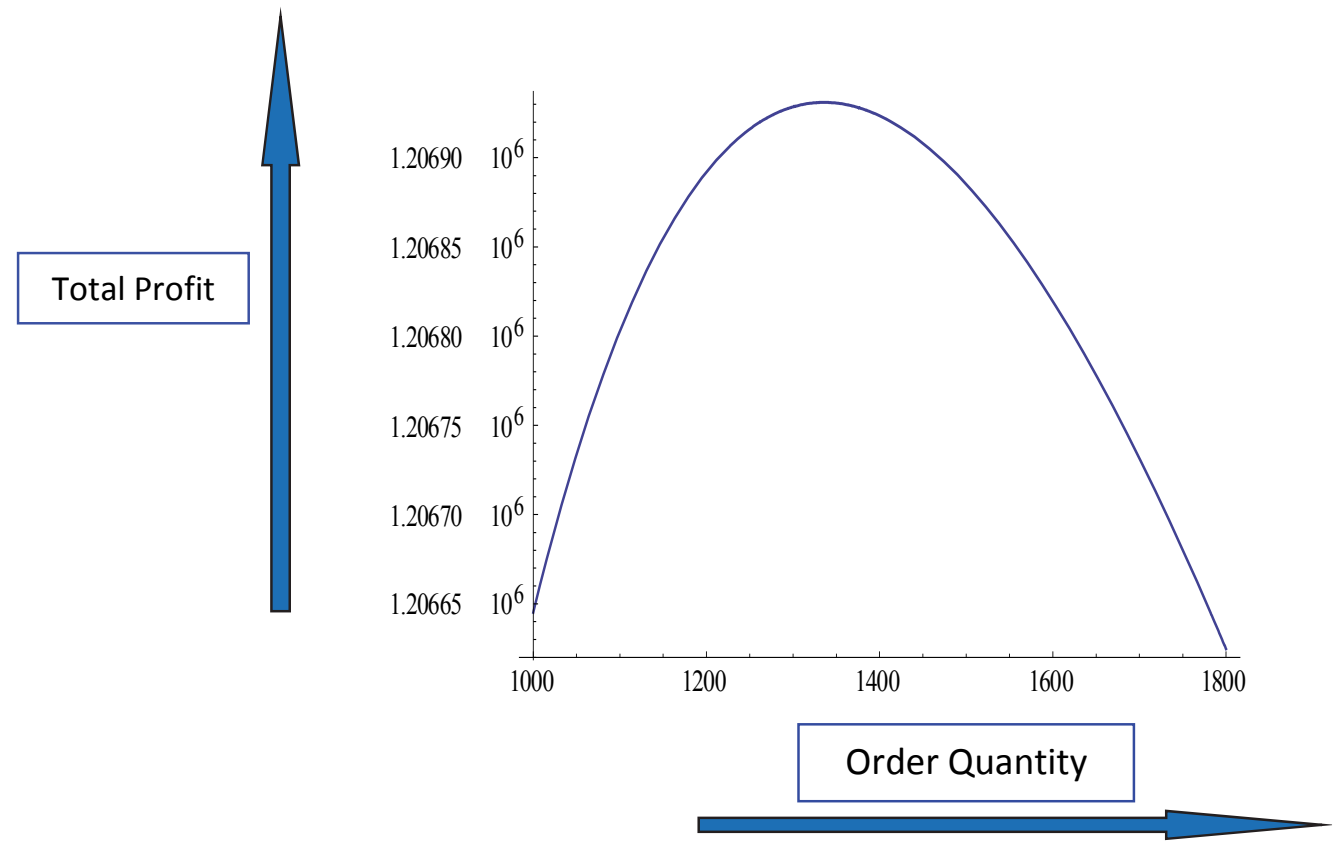

Fig. 5. The concavity of the whole worth functions per cycle versus order quantity for case-2

\section{Algorithm}

Stage-1: Find out $y_{n}{ }^{*}=y_{n 1}\left(\right.$ say) from Eq. (11). Now, replacing the value of $y_{n 1}$ and computing the values $T_{n}$ and $t_{n}$ from Eq. (3) and Eq. (4). If $T_{n} \geq t_{n} \geq M$, then the maximum whole worth is derived from Eq. (9a). 
Stage-2: Find out $y_{n}{ }^{*}=y_{n 1}\left(\right.$ say) from Eq. (15). Now replacing the value of $y_{n 1}$ and calculating the values $T_{n}$ and $t_{n}$ from Eq. (3) and Eq. (4). If $T_{n} \geq M \geq t_{n}$ then the maximum whole worth is derived from Eq. (9b).

Stage-3: Find out $y_{n}{ }^{*}=y_{n 1}\left(\right.$ say) from Eq. (18). Now replacing the value of $y_{n 1}$ and calculating the values $T_{n}$ and $t_{n}$ from Eq. (3) and Eq. (4). If $M \geq T_{n} \geq t_{n}$ then the maximum whole worth is derived from Eq. (9c).

Stage-4: Compare the calculated worth for case-1, case-2, and case-3 at $M$ and to choose an optimal value of $y_{n}$ associated with maximum worth.

\section{Numerical example}

An example is illustrated for the impact of allowable late cash expenses on this model with imperfect quality items under learning effect.

\subsection{Example for Case-2 $\left(t_{n} \leq M \leq T_{n}\right)$}

Most of the input parameters in this example are obtained from Jaber et al. (2008), which are given below:

$$
\begin{aligned}
& D=50000 \text { Units } / \text { years, } K=\$ 100, h=\$ 5 \text { Unit } / \text { year, } \chi=175200 \text { Units, } d=\$ 0.5 / \text { Unit }, \\
& c_{s}=\$ 20 / \text { year }, c=\$ 25 / \text { Unit }, p=\$ 50 / \text { year, } p(n)=0.0397478, n=1, a=40, b=1, g=999, \\
& I_{e}=0.06 / \text { year, } I_{p}=0.12 / \text { year, } M=.013 \text { year. }
\end{aligned}
$$

By the help of the proposed algorithm we get the optimal order quantity, $y^{*}{ }_{n}=1336$ (units) per year and putting the optimal value of $y_{n}{ }_{n}=1336$ in Eq. (7), we get retailer's profit $\psi_{1}\left(y_{n}{ }^{*}\right)=1.20693 \times 10^{6}$, screening time $t_{n}=y_{n} / \chi=.0076$ year and cycle length, $T_{n}=0.025$ year. If seller offers no tradecredit period, $M=0$, then retailer's gets optimal order quantity and profit are $y^{*}{ }_{n}=1455$ and $\psi_{n}\left(y_{n}^{*}\right)=1.2065 \times 10^{6}$. For maximization of profit with respect to the retailer's optimal ordering, the necessary condition is satisfied from Equation (17). After simplification of Eq. (17), we get $\frac{d^{2} \psi_{2}\left(y_{n}\right)}{d y_{n}{ }_{n}}=-41.5<0$, where $y_{n}=1336$. The results clearly suggest that it is advantageous to adopt trade-credit financing policy in this inspection model for the retailer with imperfect quality of items.

\section{Sensitivity Analysis}

Sensitivity analysis is performed on the basis of key parameters to determine the robustness of the model including the fraction of imperfect items, trade-credit period $(M)$, interest earned $\left(I_{e}\right)$, interest charged $\left(I_{p}\right)$, number of shipment $(n)$, defective percentage items $(p(n))$, on the ordered lot $\left(y_{n}\right)$ as well as retailer's whole profit per cycle.

Table 1

Impact of trade credit period on the total profit for case-2

\begin{tabular}{ccccc}
\hline $\begin{array}{c}\text { Credit period } \\
M \text { (Year })\end{array}$ & $\begin{array}{c}\text { Screening time } \\
t_{n}(\text { Year })\end{array}$ & $\begin{array}{c}\text { Cycle Time } \\
T_{n}(\text { year })\end{array}$ & $\begin{array}{c}\text { Order quantity } \\
y_{n}(\text { Units })\end{array}$ & $\begin{array}{c}\text { Retailer's Profit } \\
\psi_{2}\left(y_{n}\right)(\$)\end{array}$ \\
\hline 4 & 3 & 10 & 1371 & 1206720 \\
5 & 3 & 10 & 1335 & 1206930 \\
8 & 3 & 9 & 1160 & 1207880 \\
\hline
\end{tabular}




\section{Table 2}

Impact of learning rate on the total profit for case -2

Number of Shipment

(n)

$$
\begin{array}{cc}
b=1.00 \quad & \text { Learning rate } \\
b=1.20
\end{array}
$$

$b=1.40$

\begin{tabular}{cccc} 
& Case-2 & Case-2 & Case-2 $\psi_{2}\left(y_{n}\right)(\$)$ \\
& $\psi_{2}\left(y_{n}\right)(\$)$ & $\psi_{2}\left(y_{n}\right)(\$)$ & \\
\hline 1 & 1206930 & 1206940 & 1206950 \\
2 & 1206990 & 1207030 & 1207090 \\
3 & 1207130 & 1207320 & 1207640 \\
4 & 1207510 & 1208180 & 1209400 \\
5 & 1208420 & 1210270 & 1212990 \\
\hline
\end{tabular}

Table 3

Effect of number of shipment on defective percentage, order quantity and total profit for case-2

\begin{tabular}{cccc}
\hline $\begin{array}{c}\text { Number of } \\
\text { shipment }\end{array}$ & $\begin{array}{c}\text { Defective percentage in a per lot, } \\
p(n) \text { (per cycle) }\end{array}$ & Order quantity $y_{n}($ Units $)$ & $\begin{array}{c}\text { Retailer's Profit } \\
\psi_{2}\left(y_{n}\right)(\$)\end{array}$ \\
\hline 1 & & & 1206930 \\
2 & 0.0399317 & 1335.72 & 1206990 \\
3 & 0.0397478 & 1335.54 & 1207130 \\
4 & 0.0392579 & 1335.14 & 1207510 \\
5 & 0.0379890 & 1334.04 & 1208420 \\
\hline
\end{tabular}

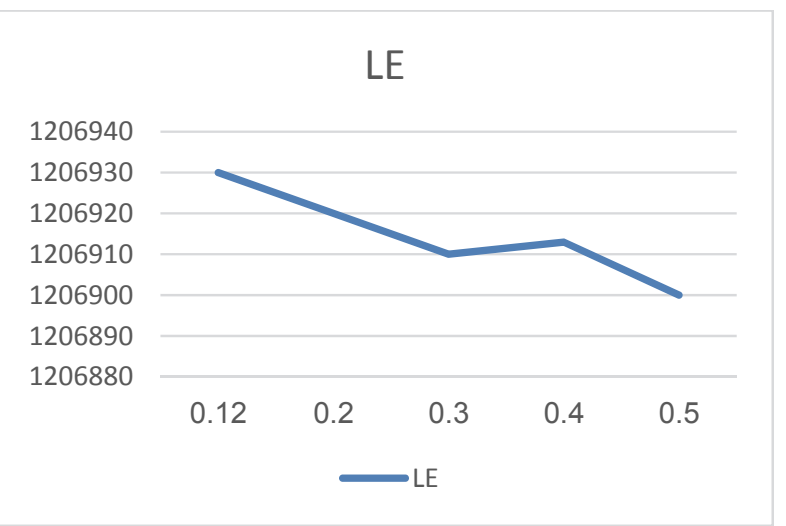

Fig. 6. Impact of interest paid on the total profit for case-2

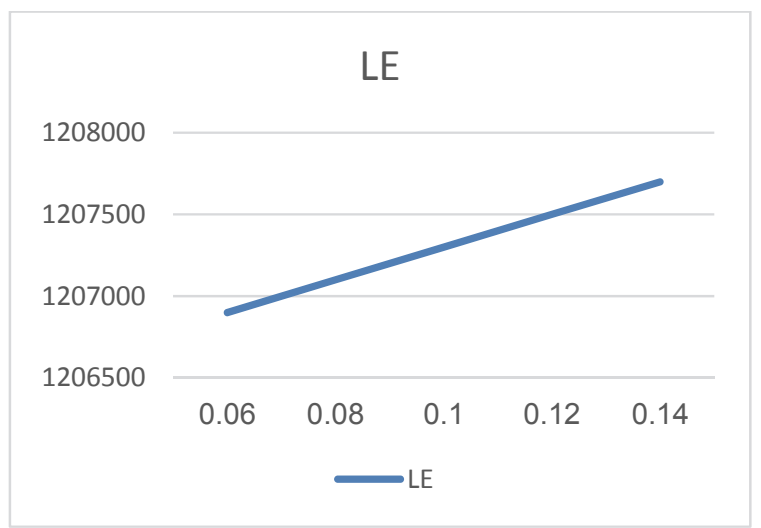

Fig. 7. Impact of interest gained on the total profit for case-2

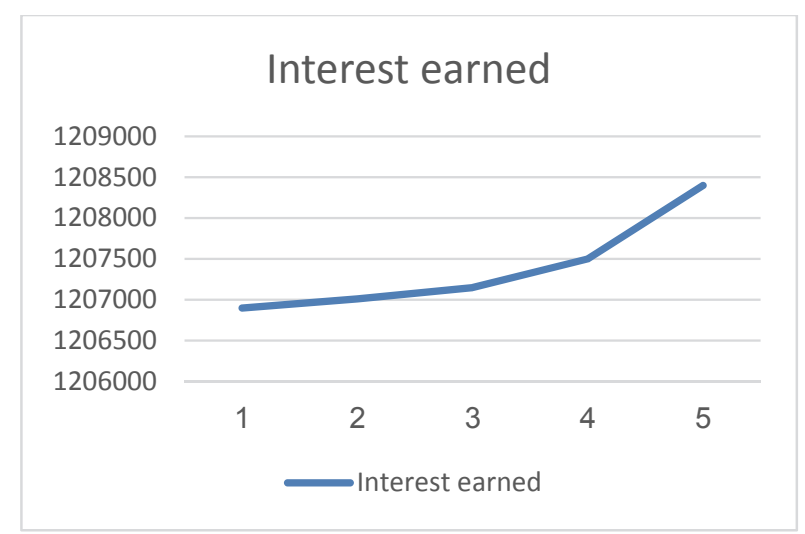

Fig. 8. Impact of number of shipment on the total profit for case-2 


\subsection{Observations}

All observations from Tables (1-3) and Figs. (6-8) are based on computational results, and the subsequent decision-making insights have been derived. It can be seen that from Table 1, as the value of $M$ increases, correspondingly the retailer's total worth increases due to income of sales revenue and interest gained and this trend is similar to the one in case-2. It can be easily seen table-2 (case-2) the learning rate increases from 1.00 to 1.40 with the number of shipments, the retailer's whole worth per cycle in each cases increase due to defective percentage quality items, good quality items as well as interest gained. It can be easily seen that from the table-3 (for case-2) that if the number of shipments increase, then defective percentage and unequal lots size decreases but the total worth per cycle in each case increases. Similarly it can be observed that from figure-8 (case-2), if the number of shipments increase, then the total worth per cycle, in each case increases due to the learning effect. Further from Fig. 7, we observe that the increasing values of $I_{e}$ and the total worth per cycle in each case increases and from Fig. 6, we find out that when the value of interest paid increases, the retailer's whole worth per cycle decreases.

\section{Discussion}

Learning curves is an alternative promotional mathematical tool for the buyer to minimize cost on order to get maximum profit in business. This model reflects on how much order quantity should be given to the buyer. Buyers want to minimize the total cost for more profit, accepting the learning phenomenon in which they learn new tasks after frequent repetition. In this article, brief presentation of the solutions of such types of stock-learning problem has been shown. After getting all the values from above three cases, we conclude that the maximum profit was given by case-3 $\left(t_{n} \leq T_{n} \leq M\right)$. But this is not always the situation that the credit period lies beyond the total cycle length $\left(T_{n}\right)$. It is not beneficial from the seller's point of view. So after pondering upon the same, we consider that, case- $2\left(t_{n} \leq M \leq T_{n}\right)$ is perfect for any situation. This case gives the approximate value for all the parameters.

\section{Conclusion}

Present paper improved the model of Jaber (2008) using trade credit financing with percentage defective in a shipment decrease in conformance with learning effect. Trade credit financing is a promotional tool for retailer's during business and maximizes the profit. This paper explained already in the example, if retailer offered no trade credit period then he received less profit and if he provided trade credit period then he received more profit. This model optimized the order quantity and corresponded the profit of retailer with some parameters, like number of shipments, interest earned, and interest paid under the condition of trade credit period. A compressive sensitivity studied was also done to explore the effects of key parameters like interest earned interest paid and number of shipments on the optimal output and how. Buyer gained more profit due to increase in credit period. So, we eventually concluded that retailers must obtain the gain of permissible delay payments more often and must order a smaller size.

\section{References}

Aggarwal, S. P., \& Jaggi, C. K. (1995). Ordering policies of deteriorating items under permissible delay in payments. Journal of the operational Research Society, 46(5), 658-662.

Balkhi, Z. T. (2003). The effects of learning on the optimal production lot size for deteriorating and partially backordered items with time varying demand and deterioration rates. Applied Mathematical Modelling, 27(10), 763-779.

Givi, Z. S., Jaber, M. Y., \& Neumann, W. P. (2015). Modelling worker reliability with learning and fatigue. Applied Mathematical Modelling, 39(17), 5186-5199. 
Globerson, S., Levin, N., \& Shtub, A. (1989). The impact of breaks on forgetting when performing a repetitive task. IIE transactions, 21(4), 376-381.

Jaber, M. Y., \& Bonney, M. (1997). A comparative study of learning curves with forgetting. Applied Mathematical Modelling, 21(8), 523-531.

Jaber, M. Y., \& Bonney, M. (2003). Lot sizing with learning and forgetting in set-ups and in product quality. International Journal of Production Economics, 83(1), 95-111.

Jaber, M. Y., \& Bonney, M. (1996a). Production breaks and the learning curve: the forgetting phenomenon. Applied mathematical modelling, 2(20), 162-169.

Jaber, M. Y., \& Bonney, M. (1996b). Optimal lot sizing under learning considerations: The bounded learning case. Applied Mathematical Modelling, 20(10), 750-755.

Jaber, M. Y., Goyal, S. K., \& Imran, M. (2008). Economic production quantity model for items with imperfect quality subject to learning effects. International Journal of Production Economics, 115(1), 143-150.

Jaber, M. Y., \& Guiffrida, A. L. (2004). Learning curves for processes generating defects requiring reworks. European Journal of Operational Research, 159(3), 663-672.

Jaber, M. Y., \& Guiffrida, A. L. (2008). Learning curves for imperfect production processes with reworks and process restoration interruptions. European journal of operational research, 189(1), 93-104.

Jaber, M. Y., \& Khan, M. (2010). Managing yield by lot splitting in a serial production line with learning, rework and scrap. International Journal of Production Economics, 124(1), 32-39.

Jaber, M. Y., \& Salameh, M. K. (1995). Optimal lot sizing under learning considerations: Shortages allowed and backordered. Applied Mathematical Modelling, 19(5), 307-310.

Jaggi, C. K., Goel, S. K., \& Mittal, M. (2013). Credit financing in economic ordering policies for defective items with allowable shortages. Applied Mathematics and Computation, 219(10), 52685282.

Khan, M., Jaber, M. Y., \& Wahab, M. I. M. (2010). Economic order quantity model for items with imperfect quality with learning in inspection. International journal of production economics, 124(1), 87-96.

Konstantaras, I., Skouri, K., \& Jaber, M. Y. (2012). Inventory models for imperfect quality items with shortages and learning in inspection. Applied Mathematical Modelling, 36(11), 5334-5343.

Salameh, M. K., Abdul-Malak, M. A. U., \& Jaber, M. Y. (1993). Mathematical modelling of the effect of human learning in the finite production inventory model. Applied mathematical modelling, 17(11), 613-615.

Salameh, M. K., \& Jaber, M. Y. (2000). Economic production quantity model for items with imperfect quality. International journal of production economics, 64(1-3), 59-64.

Teng, J. T., Lou, K. R., \& Wang, L. (2014). Optimal trade credit and lot size policies in economic production quantity models with learning curve production costs. International Journal of Production Economics, 155, 318-323.

Wright, T. P. (1936). Factors affecting the cost of airplanes. Journal of the aeronautical sciences, 3(4), $122-128$

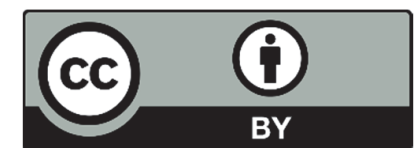

(C) 2019 by the authors; licensee Growing Science, Canada. This is an open access article distributed under the terms and conditions of the Creative Commons Attribution (CC-BY) license (http://creativecommons.org/licenses/by/4.0/). 